\title{
Standards of Textuality: Rendering English and Persian Texts Based on a Textual Model*
}

\author{
Hamidreza Hossein Mikhchi \\ Islamic Azad University
}

\begin{abstract}
The paper first reports on the standards of textuality which emanate from different ideas of scholars and how the standards' roles work in translation. Secondly, a textual model of translation is proposed, which features the way standards of source and target text could communicate, the importance of translator's triad (knowledgeideology-creativity) and the direct effects of external agents on translation. Thirdly, to better understand the practicality of the model, excerpts of two English novels with their corresponding Persian translations are analyzed in detail and evaluated.
\end{abstract}

Keywords: Textuality, standards of textuality, textual model, communicating, translator's triad, direct effects

\footnotetext{
* Dr. Gholamreza Tajvidi has made a scholarly contribution to the rough draft of the article. His help is gratefully acknowledged.
}

Hamidreza Hossein Mikhchi Islamic Azad University, Science and Research Campus of Tehran No. 16, Motahari, Sharak-E-Zhandarmeri, Tehran, Iran Phone: +98-21-88262813; Email: h.mikhchi@gmail.com 
48 Standards of Textuality

\section{Introduction}

Pondering about translation is almost as old as translation itself. The most eminent and astute translators have mulled over the different ways to link the chasm between the source and the target text. Looking at the written texts shows the process of translation could sometimes lean towards either source or target text. For instance, as Hatim (2001: 43) describes that it could move towards the models which focus on source like formal equivalence: Catford, dynamic equivalence: Nida, pragmatic equivalence: Koller, textbased equivalence: Beaugrande, foreignisation and equivalence: Venuti; or it might shift towards the target text like translation as metatext: Holmes, translation as re-writing: Bassnett and Lefevere, transformation: the feminists, deconstructionists, manipulationists, polysystem and norms: Toury, skopos: Reiss and Vermeer.

Beyond diverging models which operate in different fields and modes of translating, the textual model, the approach discussed in this paper, focuses on both source and target text. As we will see, the text is a set of mutually relevant communicative functions that hang together and are constructed in such a way as to respond to a particular context and thus achieve and overall rhetorical purpose (Hatim \& Mason 1997: 224) and the translator (communicator) is the one who tries to communicate concepts of the source to the target. Assuming the source as a text, we believe the adequacy of translation is achieved when the target (translation of the source text) would be a text which communicates like the source text.

Textuality, a linguistically oriented work on translation was primarily initiated by scholars like Beaugrande (1981), Neubert and Shreve (1992), Hatim and Mason (1997) who have made valuable contributions to both textual approach and translation. In this article, their ideas on textuality are juxtaposed to shed light on more delicacies of the field and pave the way for establishment of a reliable model. 


\section{Textuality}

Since they can often only be completely understood in relation to the context in which they occur and communicate a particular function or purpose, texts are thought of as a more appropriate unit of analysis for many purposes like translation. To consider phrases, clauses, sentences, and paragraphs as units of translation, while they used to be used in some models of translation, we will see that texts can be regarded more comprehensive and practical units of translation; however, the units mentioned have occasionally been taken as texts too. So, what exactly is a text? Is it just a unit of analysis similar or larger than the formers?

A text can be defined as an actual use of language, as distinct from a sentence, which is an abstract unit of linguistic analysis. We identify a piece of language as a text as soon as we recognize that it has been produced for a communicative purpose (Widdowson 2007: 4). The communicative purpose is an essential aspect of a text because, in the actual use of language i.e. text, it is a means to connect the reader to the text. The connection is to transfer meaning and intention of the text's author, who is one of the parties involved, to the reader, who is another party. As a text is read, the reader is placed in a state created by the communicative purpose. If a text does not communicate, its reader will not realize the meaning and intention of that text.

Linguistically speaking, text is a communicative occurrence which meets seven standards of textuality. If any of these standards is considered not to have been satisfied, the text will not be communicative. Again, non-communicative texts are treated as nontexts. These standards include: cohesion, coherence, intentionality, acceptability, informativity, situationality, and intertextuality (Beaugrande \& Dressler 1992). It may be noted, that these standards are the constitutive principles defining communicative purpose of the text. They realize us how occurrences are connected to the others: 
through syntactic relations on the surface (cohesion); through conceptual relations in the text (coherence); through the attitudes of the author and reader to the text (intentionality and acceptability); through the transfer of the information (informativity); through the setting (situationality); and through the reciprocal relationship of separate texts (intertextuality).

On the other hand, to give explicit linguistic expression in a text, textuality is a property that a complex linguistic object (the text) assumes when it reflects certain social and communicative constraints. The operation of these constraints is manifested in recognizable linguistic patterns at the textual surface. Textuality is induced by the linguistic surface but is not confined to it. The linguistic surface of a text is no more than a pointer to its textuality (Neubert \& Shreve 1992: 70). By investigating the textual surface, regarding the standards of its textuality via textual analysis, which is the main objective of the current paper, one may be able to unravel the complexity of linguistic features of the surface, analyze the relationships between constituents of the text, and ultimately, learn about the meaning and intention of the text which relate to social and communicative constraints comprised the context.

Assuming there are linguistic mechanisms that combine the standards of textuality to create the text, we might perceive that the primary duty of the translator is to discover how the standards of textuality of source texts hold the communicative purpose of the texts. Furthermore, discerning linguistic mechanisms of the standards of textuality of target texts could help the translator to better convey the meaning and intention of the source text into the target. In this view, translatability relies on the potential for textualization and, more broadly, on the potential for communication. Textualization is the global strategy that makes translation possible (ibid. 133-147).

To better understand the concept of textuality and how it could work in translation, the sub-following sections have been concerned, 
mostly by scholars' points of view, with specifying seven defining characteristics of text -- the set of standards of textuality which refers to all texts that owns communicative purpose -- to provide part of the foundation of the textual model which deals with text processing.

\subsection{Cohesion}

Cohesion is the first of the seven standards, and has the function of attaching, syntactically and lexically, the text together in order to create textual unity. It is a function of syntax in communication that imposes organizational patterns upon the surface text (the presented configuration of words) (Beaugrande \& Dressler 1992: 48). Hatim and Mason define a cohesive text as:

A text is cohesive in the sense that the various components of the surface text (the actual words we see) are mutually connected within a sequence of some kind. In terms of both lexis and grammar, that is, the surface components depend upon each other in establishing and maintaining text continuity. (1997: 15)

Cohesion is obtained from five main ways of markers of cohesive relationships: references, substitutions, ellipsis, junctions, and lexical cohesion. To be cohesive, a text probably consists of short-range stretches of the surface structure which are set up as closely-knit patterns of grammatical dependencies; long-range stretches, in contrast, could be handled by re-utilizing previous elements or patterns, economizing were possible (Beaugrande \& Dressler 1992: 79).

Among the standards of textuality, cohesion is the most probably linguistic; cohesion is a property of the linguistic surface of the text. 
The linguistic elements that occur in sequences of sentences act together to form texture, a term which refers to cohesive ties at the level of connected discourse (as opposed to cohesive ties within individual sentences). Cohesion makes coherence linguistically evident. The cohesive text is, as a result, the end product of translation (Neubert \& Shreve 1992: 102-103).

\subsection{Coherence}

Coherence in contrast to cohesion includes the layout and ordering of the concepts and relations of the text which are caught on by the surface text.

According to Hörmann (1976), continuity of senses is defined as the foundation of coherence which results from the configuration of concepts, expressed relations, and the receivers' knowledge of the world. He notes:

A text makes sense because there is a continuity of senses among the knowledge activated by the expressions of the text. A senseless or non-sensical text is one on which text receivers can discover no such continuity, usually because there is a serious mismatch between the configuration of concepts and relations expressed and the receivers' prior knowledge of the world. We would define this continuity of senses as the foundation of coherence, being the mutual access and relevance within a configuration of concepts and relations. (cited in Beaugrande \& Dressler 1992: 84)

The continuity of senses created by coherence is, in fact, the interpretation of the text that readers (if the text is written) appreciate and make sense of. The lack of the continuity of senses disturbs the communication purpose of the text.

On the other hand, Grice's maxims of manner and relation tell us 
that there is order imposed on the information content. This order is a logical structure which defines the semantic connections between information units in the text. "Coherence is the connection of individual information elements with a certain logical structure" mention Neubert \& Shreve (1992). They say that

coherence is a property which texts assume when their information contents take on such a logical structure ... Coherence is not an information unit; it is the connection of individual information elements to create larger, more global structures of meaning. (Neubert \& Shreve 1992: 93-96)

Also, Hatim \& Mason (1990) after criticizing the views which believe that coherence is not something which is created by text, but rather an assumption made by language users that, in accordance with the cooperative principle, texts are intended to be coherent (194), define coherence as the procedures which ensure conceptual connectivity, including (1) logical relations, (2) organization of events, objects, and situations; and (3) continuity in human experience (195).

A coherent text has an underlying logical structure that acts to guide the reader through the text. This structure helps the reader overcome his ignorance of specific details. The maintenance of coherence could be established as a criterion for adequate translation; because in this sense, translatability refers to the way that a text makes sense to the readers through the organization of its content, and the relevance and comprehensibility of its concepts and ideas. In essence, coherence is not imported from the source text; coherence is constructed anew in the target text using the source sense relations as a template. Re-establishing coherence is an example of how translation is a creative textual act (Neubert \& Shreve 1992: 95-100). 


\subsection{Intentionality and Acceptability}

To produce a cohesive and coherent text, one follows Grice's maxims and develops the notion of speech acts in order to reach the desirable intention. Beaugrande \& Dressler introduce the notion of intentionality to subsume the intentions of text producers. In the most immediate sense of the term, the producer intends the language configuration under production to be a cohesive and coherent text (1992: 113). A text must be intended to be a text and accepted as such in order to be utilized in communicative interaction, i.e. the author of the text should intend it to contribute towards some goal and the reader of it should accept that it is, in fact, satisfying some such objective.

Neubert \& Shreve (1992) also say that intentionality is meant to sensitize us to the correlation between intentions and texts, and from the reader's point of view, intentionality is connected with relevance, a measure of the importance he or she attaches to the information. Intentionality and relevance are a sender-receiver (translatorreceiver) pairing (72).

More specifically, Hatim \& Mason (1997) define the concept of intentionality from two highly abstract and relatively concrete terms:

At a fairly high level of abstraction, intentionality involves the text producer's attitude that the text in hand should constitute a cohesive and coherent whole and that it should intertextually link up with a set of socio-textual conventions recognizable by a given community of text users. At a more concrete level of analysis, on the other hand, intentionality comprises a set of goals. These may be achieved locally by relaying intended meanings or globally by contributing to the mutual dependence of the various intentions within an overall plan of the entire text. (19) 
Obviously, in real situations, intentionality is inevitably involved in the text producer's desire to be part of particular social institutions and processes, to be power- or solidarity-oriented, or to adopt a particular distance with regard to the addressee and the object of description (ibid. 22).

The notion that intentionality fully meets texts with cohesive and coherent texture is not entirely verified. To attain the desirable intention, one may violate Grice's maxims when it is expedient to fulfill or signify the intended meaning or effect. As Beaugrande \& Dressler (1992) point out:

People can and do use texts which, for various motives, do not seem fully cohesive and coherent. We should therefore include the attitudes of text users among the standards of textuality. A language configuration must be intended to be a text and accepted as such in order to be utilized in communicative interaction. These attitudes involve some tolerance toward disturbances of cohesion or coherence, as long as the purposeful nature of the communication is upheld. The production and reception of texts function as discourse actions relevant to some plan or goal. (111)

In some cases, there are many highly conventional texts where format and sense clearly indicate the underlying purpose. Texts like instruction manuals, patents, and legal contracts likewise clearly indicate their underlying intentionality. At the other end of the spectrum are difficult poetic texts whose intentions are more obscure (Neubert \& Shreve 1992: 72).

In the process of translation, the translator needs to extract the intentionality of the source text; therefore, he or she might obtain the intent of the author. But as Neubert and Shreve believe, intentionality is not really about an author's intent, because sometimes the text does not accomplish what the author intends. 
Intentionality is about the effects of an author's or translator's decisions on the text and their subsequent impact on the receptive intentions of the reader (ibid 72).

To describe acceptability, Beaugrande \& Dressler (1992) say that it is the text receivers' attitude in communication. In the most immediate sense of the term, text receivers must accept a language configuration as a cohesive and coherent text capable of utilization (129). The primary goal of text producer is to appraise the addressee from her intent. Any text is written to be accepted. In this case, Neubert \& Shreve (1992) believe:

Acceptability does not necessarily imply that the receiver believe the specific contents of the text. It does require that the addressee be able to identify and extract those contents (what the text is supposed to do). ... The receiver must be able to determine what kind of text the sender intended to send, and what was to be achieved by sending it. (73)

Regarding the translator as a communicator, we do not isolate the intentionality from the acceptability because their concepts are combined at the communication. Hence, to analyze texts, some theoreticians like Hatim \& Mason (1997) just use the concept of intentionality in order to refer to both.

\subsection{Informativity}

Texts consist of information and a criterion of that is the informativity of the text. To define informativity, Beaugrande \& Dressler (1992) believe in the new and unexpected notion of a presentation. They use the term informativity to designate the extent to which a presentation is new or unexpected for the receivers. Usually, the notion is applied to content; but occurrences in any language system might be informative (139). On the other hand, 
according to Neubert \& Shreve (1992), the substantive knowledge content is considered. They say that informativity is a function of what is delivered by the text; it is a function of its substantive knowledge content. The translator's commission is to create a linguistic surface that will allow the L2 user to retrieve from the text the same knowledge content that was in the L1 original (90). Also, for Hatim \& Mason (1997), the idea of knownness is seen. They argue that informativity concerns the extent to which a communicative occurrence might be expected or unexpected, known or unknown, certain or uncertain and so on (26).

One of the most important duties of the translator is to relate the reader to the information of the text. Because of lexical and syntactical differences of languages, the order of informativity -distribution of information -- changes in translation; hence, informativity of the text has to be dominated by the coherence to make sense for the reader. Neubert \& Shreve (1992) claim that the order of informativity is a measure of the significance of the information units in a text. This measure is relative to the other information items in the text (90).

The other point for conceiving the content of the text relates to the presupposition of the reader. Neubert \& Shreve note that it is difficult to compensate for the fact that the L2 community has no experience with the kind of text being translated ... Reconstruction is blocked because the L2 user cannot recognize the elements of the network and their relations. The translator may have to intervene by inserting footnotes, providing translator's notes, or creating explanatory paraphrases (1992: 90-91).

\subsection{Situationality}

Texts are endowed with a degree of relevance or situationality in as much as they hold a certain communicative purpose and relate communicate act (discourse) to the situation. In fact, it is essential 
for the evaluation of the situationality of a text to know where it happened and what its function was in the situation. Beaugrande \& Dressler (1992) define the term situationality as "a general designation for the factors which render a text relevant to a current or recoverable situation of occurrence ... the accessible evidence in the situation is fed into the model along with our prior knowledge and expectations about how the 'real world' is organized" (163).

Situationality is the location of a text in a discrete sociocultural context in a real time and place (Neubert \& Shreve 1992: 85). The more discrete is the situationality of two texts, the more difficult is to manage them during translation, however, as Neubert \& Shreve believe, many texts have a common situationality. This may happen cross cultural and linguistic boundaries (ibid. 87). Hatim \& Mason say:

In pursuing the intended goals, translators (as a special category of text receivers and producers) seek to relay to a target reader what has already been communicated by a text producer and presented with varying degrees of explicitness in the text. The question we ought to address at this juncture is whether a given sequence of cohesive and coherent linguistic elements, intended to display a particular intertextual potential, is actually appropriate to a given situation of occurrence. This property of texts is known as situationality. (1997: 20)

Situationality is the central issue in translatability. If a translation is to succeed, there must be a situation which requires it. There must be a translation need. The situationality of the translation is never the same as the situationality of the source text (Neubert \& Shreve 1992: 85).

The general strategy of the translator is to adjust the text to its new situation. Adjustments may involve a variety of translation 
procedures, including explicitation, compression, recasting, and textual re-arrangements ... the modifications are motivated by the need to preserve the intentionality and functionality of the text in its new situation (ibid. 87).

\subsection{Intertextuality}

The final standard (intertextuality) refers to the relationship between a certain text and other texts which share characteristics with it; the factors which allow readers to distinguish, in a new text, features of other texts that they have experienced. In other words, intertextuality subsumes the ways in which the production and reception of a given text depends upon the participants' knowledge of other texts (Beaugrande \& Dressler 1992: 182). It is likely that the impression that a translation "sounds wrong" comes from violations of a reader's textual expectations. The reader has in mind a set of tacit expectations about what the text "should be like." This set of expectations is a product of intertextuality (Neubert \& Shreve 1992: 117).

Intertextuality is a function of a configuration of grammatical and lexical properties. It is a global pattern which the reader compares to pre-existing cognitive templates abstracted from experience. It is a property of "being like other texts of this kind" which readers attribute to texts. If the translator wants to create a translation that appears natural, then he or she should create a text whose linguistic surface evokes a similar recognition. The translation has to possess the intertextuality of the target culture's natural texts (ibid. 117-).

Hatim \& Mason (1990: 131) suggest that the theory of intertextuality

seems to be taking us in two different directions. On the one hand, it underlines the importance of the prior text, 
advocating that a literary text, for example, is not to be considered as an autonomous entity but as a dependent intertextual construct. On the other hand, by focusing on communicative intent as a precondition for intelligibility, intertextuality seems to indicate that the status of a prior text may only be seen in terms of its contribution to a code which evolves as the text unfolds.

Language contact is primarily textual contact. It is the impact of L1 texts on L2 texts that produces language change. Modern communication has introduced new textual conventions into target languages; therefore, every translation can be seen as having a double intertextuality. The source text has intertextual relationships with other source-language texts. The translation will establish new relationships with existing $\mathrm{L} 2$ texts. The translator cannot ignore the relationship between target text and original text. Confronted with this double intertextuality, the translator must act in favor of the target language text world (Neubert \& Shreve 1992: 118-121). Totally speaking, the whole notion of textuality may depend upon exploring the influence of intertextuality as a procedural control upon communicative activities at large (Beaugrande \& Dressler 1992: 206).

\section{Textuality as a Secure Translation Model}

Translating is looked upon as an act of communication which attempts to relay, across cultural and linguistic boundaries, another act of communication (which may have been intended for different purposes and different readers/hearers) (Hatim \& Mason 1997: 1). With this in mind, one needs, on the one hand, to thoroughly analyze the source text in order to unravel any complex and thorny points of the text, and on the other hand, to communicate the 
extracted information to the target text. But the question here is how can a translator be sure that she is properly communicating the right meaning between the texts?

To suggest a solution, textuality is referred by which at the first step, one analyzes the text based on its basic standards of textuality and, at the second step, the translator, previously having known the basic standards of textuality of the target text, synthesizes source textual features into the target text. To put it another way, while we assumed any text has a communicative purpose, the translator (communicator) needs, firstly, to do textual analysis on the source text to receive the messages -- the meaning and intention -- encoded in the communication system of the source text. The textual analysis on the source text is a means which one can analyze the standards of the text to comprehend the message. Secondly, the translator has to communicate the messages transmitted in the source text and re-encodes them in the target text. Indeed, the translation process would be successful when the target text is a text with a communicative purpose likewise the source text. But the problem here is that sometimes the concerned standards between the texts are less manageable (linguistically speaking, static) and sometimes they are more manageable (linguistically speaking, dynamic). In this case Hatim \& Mason (1997) say:

At one extreme, there will be those local- and global-level textual occurrences which display maximal cohesion and consequently maximal coherence, where intertextuality is least intricate, intentionality least opaque, situationality least cumbersome and informativity sparingly used. At the other extreme, there will be local- and global-level textual occurrences where cohesion is not straightforward and where coherence is problematical to retrieve. In such cases, values yielded by other factors such as intentionality and intertextuality become slightly less transparent. (27) 
Needless to say, when the standards of textuality between the texts conform to each other, the creativity of the translator is needed at its minimal level; however, when they are not matched across the texts, translator's creativity is highly required. More specifically, in case of convenient matches, there are, also, lots of open options before the translator to choose from; hence, the importance of creativity is again remarkable. Totally speaking, as Landers (2001: $\mathrm{X})$ describes that translation problems are not like math problems that have only one or at most a strictly limited number of right answers ... translation is subjective in essence.

It is important to realize that analyzing a text based on textuality is essentially an abstract endeavor. The combination of the standards of textuality makes a text an actual use of language produced for a communicative purpose. Furthermore, the interpretation of a text, which depends on proper analyzing relating to the situation in which text analyst by encoding conventions tries to unravel desirable meaning, is by and large relative. As a result, to analyze a text, the translator primarily needs to contemplate, holistically, on the text as an inextricable phenomenon in which textual features make sense in close proximity; meanwhile, she should delve deeper into the context in order to shed light on convoluted relationships in the text. Nevertheless, the text analyst has to be cognizant of the delineation of his or her analyzing not related to the deviation of main purpose.

Bearing all this in mind, again to analyze a text, the only criterion that text analyst can resort to is the text itself. According to Hatim (2001):

The parameters for an adequate transfer are set by texts in communication, yielding not simply one definite meaning but rather an array of possible meanings ... the unit text may be seen in relation to "rhetorical purpose" and in terms of the way sequences of sentences are formally organized. What the text analyst is primarily concerned with would be 
the analysis of such textual phenomena as sequential relationships, intersentential structure, and text organization (33-34).

In light of this, we suggest the establishment of "translator's triad" (knowledge-ideology-creativity) which is necessary to fulfill the translation process. The triad is an important instrument which any translators must possess in order to carry the process out. To begin with, the translator should, as a communicator, owns the knowledge (and skills) of the two languages in the process of translation. She should have semantic knowledge, syntactic knowledge, and pragmatic knowledge. These are inherent in a good translator. Furthermore, the translator needs to have sufficient knowledge in both cultures; knowledge of the rules of the code governing "usage" and knowledge of how to "use" the limiting conventions. Meanwhile, ideology, a set of ideas and attitudes that strongly influence the way translator operates, is crucial to the whole process by which most of the choices are dominated in between. It has always been distinguished that translating is not a neutral process. Suffice it here to say that the variety and diversity of translated works, if not be incorrect and irrelevant, may arise from the translator's ideology that we can say, because of the diversity of ideologies, there are numerous translations that have been rendered from the same original text, making it extremely difficult to decide which one might be considered as the most accurate one (problem that will be addressed later). As mentioned earlier, creativity plays a major role in the rendering from source to the target text. At one extreme, it helps the translator picks the best option amongst variously estimated choices; at the other, it makes the translator to be unique likewise the original author who has created a unique text. Additionally, transferring the uniqueness of i.e. style of the original text to the target requires lots of creativity that the translator should possess. 
Even more importantly, there is another issue affecting on the whole mechanism that is the effect of external factors such as clients who demand the especial translation, organizations where patent the translated works, institutions with certain taste, and so on. In this respect, Pym (1998: ix) notes that it is only through translators and their " social entourage (clients, patrons, readers)" that we can try to explain why translations "happened", were produced in a particular time and place. Again, these factors have "direct effects" on the whole process of translation which could lead the text toward their direction. Obviously, the direct effects, implicitly, deviate standards of textuality of the target text from the source text; as a result, it is the translator's job to consider the effects and, by properly setting out the standards, direct the effects in a way that the least loss of communication would remain.

In what follows, we shall concentrate to put the issues discussed together in order to establish a model which may help translators in the act of translation.

\subsection{Establishment of a Textual Model for Translation}

Based on textuality, the whole mechanism of translation could be elaborated as follows. A translator by the help of her triad (knowledge-ideology-creativity) primarily tries to recognize the standards of source text and then, after recognizing the related standards of the target text compared with the standards of the source text, tries to render the textual features from source into the target text. This is what we call, the "natural current" of the mechanism; however, the direct effects of the social entourage should not be forgotten. The schematic diagram of the task would look as follows: 
Hamidreza Hossein Mikhchi 65

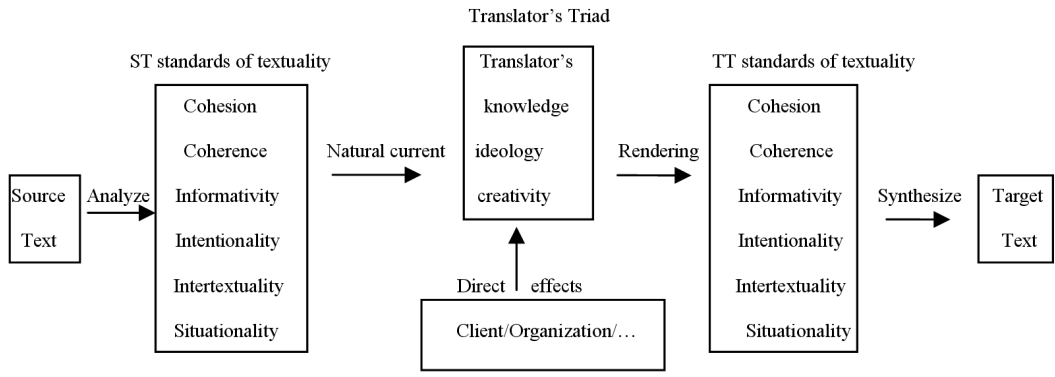

(Textual Model)

Accordingly, in this systematic approach, the analysis begins (with the help of the standards of the source) from surface text to abstract configurations of concepts (meaning, intention) and the synthesis goes (with the help of the standards) from those configurations of concepts, communicated by the source and made the context of the target, to the surface of the target text. These are, by virtue of the fact that the translator is a communicator and textprocessor, literally the same means as are employed in this article and it is for that mean that we tried to spell out what is involved in "textual model".

\section{Analyzing and Evaluating Texts Based on the Textual Model}

To illustrate how the textual model works, guiding the translator and also assessor's efforts in analyzing and rendering, let us consider an example drawn from an English novel Interpreter of Maladies by Jhumpa Lahiri and its corresponding Persian translation:

In the ninetieth paragraph of her book, Jhumpa Lahiri describes a scene in which the main male character, Mr. Kapasi, flourishing his covetously wrong thought of friendship toward Mrs. Das, the main female character, is exposing his presentiment that he may not be in 
touch with her in future, and then ...

(1) When he finished writing his address Mr. kapasi handed her the paper, but as soon as he did so he worried that he had either misspelled his name, or accidentally reversed the numbers of his postal code. He dreaded the possibility of a lost letter, the photograph never reaching him, hovering somewhere in Orissa, close but ultimately unattainable. He thought of asking for the slip of paper again, just to make sure he had written his address accurately, but Mrs. Das had already dropped it into the jumble of her bag.

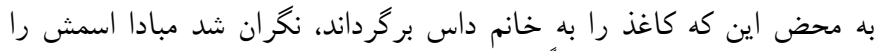

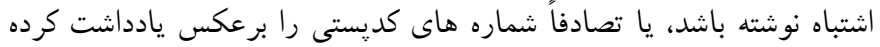

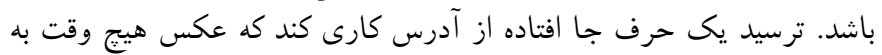

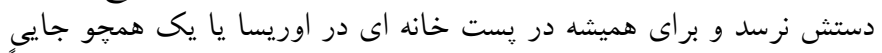

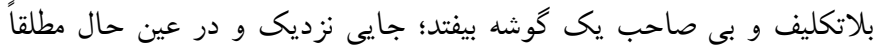

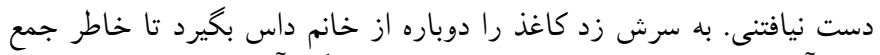

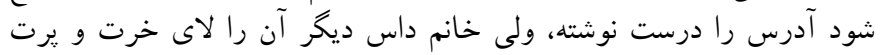
هاى ساكث انداخته بود. Be mahze inke kaghaz ra be khanome das dad, negaran shod mabada esmash ra eshtebah neveshte bashad, ya tasadofan shomarehaye kodeposti ra baraks yaddasht karde bashad. Tarsid yek harfe ja oftade az adres kari konad ke aks hichvaght be dastash naresad va baraye hamishe dar post khan ei dar orisa ya yek hamcho jaee belataklif o bi saheb yek goshe bioftad; jaee nazdik va dar ainehal motlaghan dast nayaftani. Besaresh zad kaghaz ra dobare az khanome das begirad ta khater jam shaved adres ra dorost neveshte, vali khanome das digar anra laye khert o pert haye sakash andakhte bod.

With regard to cohesion of the English text, each of the three 
sentences attempts to represent a certain image; consecutively, the translator has tried to preserve the same number of sentences and punctuation marks; however, to draw the images and to modify English structures in Persian, the number of clauses and phrases has unavoidably changed. The structure "had either misspelled ... or accidentally reversed" and its verbs' tenses have changed in Persian text, i.e. "either ... or" is not used in Persian and the tense past perfect has been replaced by a certain form of past tense which is not used in English. Because of certain arrangement of words in English, SVO, and in Persian, SOV, and also the condition of subject in English, non-pro-drop, and in Persian, pro-drop, some differences are recognized in the texts; for example, in the English text "he dreaded" has been changed to "ترسيد" (/tarsid/) which is a structure without the subject. There are lots of differences in the usage of "parts of speech" between the two languages like the reduced clause (gerund) "reaching" in the English text translated to the verb "نرسد" (/naresad/) in the Persian text.

With respect to coherence of the English text, there are eight references to the male character in the first sentence -- he, his, Mr. kapasi -- creating a significant emphasis on the man; meanwhile, the references have been reduced to five in the Persian text which are mostly implicit; in other words, the emphasis over the man in the English text creates a sort of coherence which has been reduced in the Persian text; hence, the Persian text, in this case, goes far from the author's meaning and intention. The subject pronoun "him" in the second sentence of the English text has implicitly been translated in Persian whose antecedent could already be understood by the meaning of the previous paragraph. Because of the essence of Persian language, requiring sentences to be more explicit in order to reserve the coherence of the source text, some features have been overtranslated like "close" to "جايى نزديك" (/jaee nazdik/) (back translation: close place); to put it another way, to keep the coherence, "91" words in the English text have been changed to "105" words in 
the Persian text. Due to intentionality of the second sentence in the بnglish text, "hovering" has been overtranslated to " بلا تكليف و بـ "صاحب يك گوشه بيافتد (/belataklif o bi saheb yek goshe bioftad/); nevertheless, the main author's intention which denotes "wandering" has been changed to "missing" in the Persian text.

Due to intentionality of the second sentence in the English text, بلا تكليف و بى صاحب يك گوشه "hovering" has been overtranslated to بيافند" (/belataklif o bi saheb yek goshe bioftad/), (back translation: missing and without any owner, left somewhere). Nevertheless, the main author's intention which denotes "wandering" has been changed to "missing" in the Persian text.

With respect to situationality of the English text, the word "reversed" means "incorrectly writing down"; however, it has "برعكس يادداشت كرده باشد" "whongly been rendered into the Persian text (/baraks yaddasht karde bashad/), (back translation: writing in reverse); perhaps, a right choice could be "بإنس و يبش يادداشت كرده باشد" (/pasopish yaddasht karde bashad/), (back translation: incorrectly writing down). The word "asking for" in the last sentence has been translated to "بحيرد" (/begirad/), (back translation: getting back) because of the related situation. The translator has discerned to add the word "بست خانه" (/post khane/), (back translation: post office) beside Orissa in the Persian text; it is a necessity of the Persian situationality; nevertheless, the Persian phrase "يك همجو جايى" (/yek hamcho jaee/), (back translation: somewhere like that) for the English word "Orissa" has blurred the author's meaning and intention, so in this case, situationality of the text goes wrong.

Regarding intertextuality, in the last sentence, the word "jumble" has been translated into the Persian text "خرت و يرت" (/khert o pert/), (back translation: odds and ends) which is a favorite usage of that word due to the Persian intertextuality; or the usage of collocations like "بلاتكليف و بى صاحب" (belataklif o bi saheb/) in the second Persian sentence (back translation: stuff without owners) is another instance.

To illustrate how practical the model is in evaluation of texts, let 
us consider another example drawn from an English novel The Lovely Bones by Alice Sebold and its three corresponding Persian translations:

On page 269, Sebold describes a hospital scene, in which Salmon's mother who has quit her home for a long time is going to see her hospitalized husband. While searching for the room, she is dreaming the old memories of the time when she was here, and suddenly:

(2) Her mother's ankles and oxford pumps, which she saw from the hallway, brought her back. One of the many simple things she'd lost by moving so far away, just the commonplace of her mother's feet -- their solidity and humor -- seventy-year-old feet in ridiculously uncomfortable shoes.

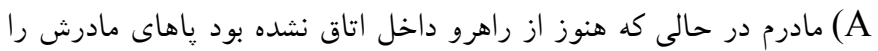

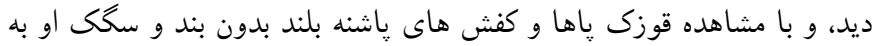

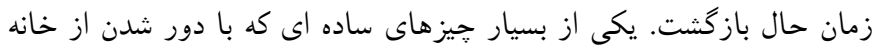

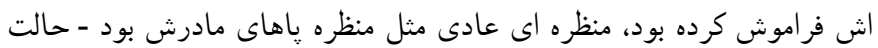

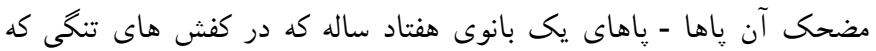
براى جوانان مناسب بود قرار دان داشت بان

A) madaram dar hali ke hanoz az rahro dakhele otagh nashode bod pahaye madarash ra did, va ba moshahede ghozake paha va kafsh haye pashne bolande bedone band va sagake oo be zamane hal bazgasht. Yeki az besyar chizhaye sadei ke ba dor shodan az khane ash faramosh karde bod, manzaree addi mesle manzaree pahaye madarash bod -- halate mozheke an paha -pahaye yek banoye haftad sale ke dar kafsh haye tangi ke baraye javanan monaseb bod gharar dasht.

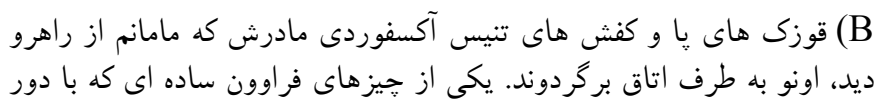




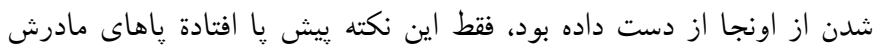

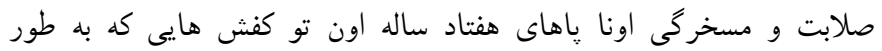
مضحكى ناراحت بودن. B) ghozak haye pa va kafsh haye tenise aksfordie madarash ke mamanam az rahro did, ono be otagh bargardond. Yeki az chizhaye faravon sadei ke ba dorshodan az onja az dast dade bod, faghat in nokte pishe pa oftadeye pahaye madarash salabat va maskharegie ona pahaye haftad sale on to kafsh haei ke betore mozheki narahat bodan.

$$
\begin{aligned}
& \text { (C }
\end{aligned}
$$

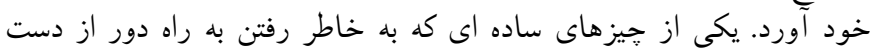

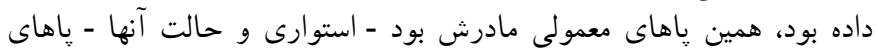

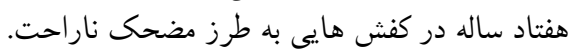

$$
\begin{aligned}
& \text { C) moche pa va kafshe aksfordie madarash ke az rahe }
\end{aligned}
$$

In the English text, the word "oxford pumps" refers to the sort of female shoes with high heels and laces; however, none of the translators has realized the real meaning of it. In this part, the information conveyed into the Persian text is completely wrong; as a result, the informativity of the text is distorted. The other word "ankles" which has two meanings in Persian -- قوزك يا، مج "- "(/moche pa, ghozake pa/) just needs the word "l " " (/moche pa/), because of the desirable situation. No Persian native speaker uses the latter word; therefore, the situationality of the text obliges the translator to choose the former word.

The author describes the scene in which the mother is walking in 
the hospital's hallway dreaming old memories and suddenly she sees her mother's feet and shoes. In order to describe this situation and to find a suitable word for "brought back", translator A has made a mistake by choosing "به زمان حال بازگشت" (be zamane hal bazgasht/), (back translation: she came back to the present) which is a wrong sentence for the situation in Persian; besides, no intertextuality in Persian confirms it. It also deviates the author's intention, when the translator paraphrases the first sentence " هنوز از راهرو داخل اتاق نشده بود " (/hanoz az rahro dakhele otagh nashode bod/). Here, the intentionality of the text is swerved from its right way and incorrect information blurs the original picture. Translator B has used the word "mother" in its informal mood "مامانم" (/mamanam/) which is an erroneous explicitation resulting to the wrong intentionality too. However, translator $\mathrm{C}$ has chosen the correct "او را به خود آورد " (/oo ra be khod avard/), (back translation: it got her back) for the "brought back", but the cohesion of the first sentence has a problem; that is, a definite article "I," (/ra/) is necessary to attach the whole sentence cohesively.

In order to render "seventy-year-old feet in ridiculously uncomfortable shoes", translator C has resorted to a literal translation "ِاهاى هفتاد ساله در كفش هايى به طرز مضحى ناراحت") (/pahaye haftad sale dar kafsh haee betarze mozhek narahat/) which is completely nonsensical in this situation. Because of Persian intertextuality, the phrase "هن:اد" (/pahaye haftad sale/) is not acceptable; in addition, Persian situationality does not accept the phrase "بك طرز مضحك ناراحت (be tarze mozhek narahat/). Perhaps,

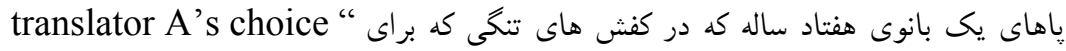
"جوانان مناسب بود قرار داشت (/pahaye yek banoye haftad sale ke dar kafsh haye tangi ke baraye javanan monaseb bod gharar dasht/) which is sort of explicitation is a better choice in this situation.

Another word "ونو" (/ono/) in translation B is a sign of wrong coherence which creates ambiguity in the text. There is no clear antecedent for it to clarify the relation; as a result, the coherence of 
the text goes wrong.

Generally speaking, in this example, because the author is trying to picture a scene and two characters with certain traits, the translator needs to closely pay attention to all details in the English text and transforms the same picture into the Persian text. Here, by the help of the textual model, one can simply analyze the texts in English and Persian and extract the desirable meanings, and render them to the target text.

\section{Conclusion}

The paper has been concerned with the activity of textprocessing which underlies human communication and is inevitably at the root of the translation process. We treated textuality as the main means of the text-processing. Textuality refers to the complex set of features that texts should have to be regarded texts. Consecutively, standards of textuality (cohesion, coherence, intentionality, acceptability, informativity, situationality, and intertextuality) were proposed as the constitutive principles defining textual communication and determine the textual characters of texts. According to the concept of textuality, if any of the standards is regarded not to have been satisfied, the text will not be communicative and is considered as non-text. We applied the concept to translation and showed that the textual characteristics (standards of textuality) might be handled through the process of translation until the target text communicates as same meaning and intention as the source text. Meanwhile, we assumed the translator's triad (knowledge-ideology-creativity) may also affect on manipulating of the standards in favor of the target text, and the direct effects which are the effect of external factors affect on the whole mechanism of translation. The whole idea of the textuality and its standards created the principle of the textual model which deals with the process of translation. In this model, the 
translator (communicator), at the one hand, tries to analyze the source text in regard to standards of textuality in order to fully grasp the hidden message (meaning and intention) of the text. Having appreciated the message, on the other hand, the translator attempts to render it, again in regard to standards of textuality, to the target text. Finally, the proposed model was employed in the assessment of some original English texts and their corresponding Persian translations. Applying the model to both English and Persian texts displayed that communicating the message of the source text to the target text through analyzing and then synthesizing the standards of textuality can be securely done.

\section{References}

Beaugrande, R. de. \& W. U. Dressler. 1992. Introduction to Text Linguistics. London, New York: Longman.

Hatim, B. 2001. Teaching and Researching Translation. Edinburgh Gate, England: Pearson Education Limited.

Hatim, B. \& I. Mason. 1990. Discourse and the Translator. London $\&$ New York: Longman.

Hatim, B. \& I. Mason. 1997. The Translator as Communicator. New York \& London: Routledge.

Lahiri, J. 1999. Interpreter of Maladies. Mariner books.

Landers, C. 2001. Literary Translation, a practical guide. New Jersey: City University.

Motarjeme dardha/ Jompa Lahiri, bargardan Amirmahdi Haghighat. ch4. Tehran: Mahi, 1385.

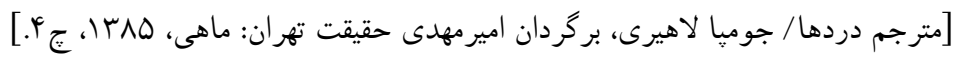

Neubert, A. \& G. M. Shreve. 1992. Translation as Text. Akron: Kent State University Press.

Ostekhanhaye dost dashtani/Alis Zibold, bargardan Faride Ashrafi. ch2. Tehran: Morvarid, 1384. 
74 Standards of Textuality

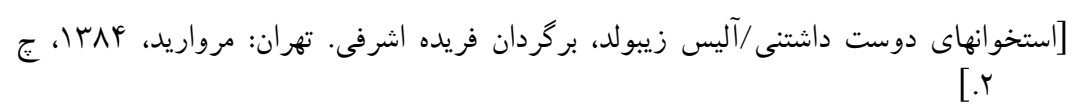

Ostekhanhaye dost dashtani/ Alis Sebald, bargardan Mitra Motazed. ch3.Tehran: Alborz, 1387.

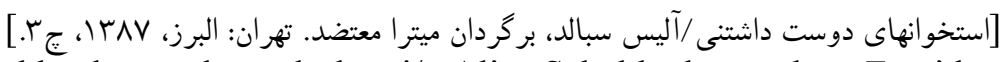

Ostekhanhaye dost dashtani/ Alis Sebald, bargardan Fereidon Ghazinezhad. Ch5. Tehran: Rozegar, 1386.

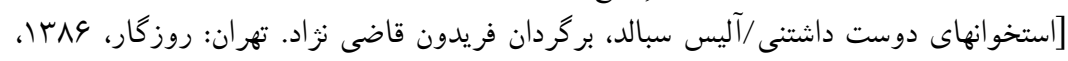

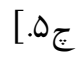

Pym, A. 1998. Method in Translation History. Manchester: St Jerome.

Sebold, A. 2002. The Lovely Bones. Great Britain: Picador.

Widdowson, H. G. 2007. Discourse Analysis. Oxford \& New York: Oxford University Press. 